\title{
Planos Municipais de Educação metropolitanos: desafios ao acompanhamento e avaliação local
}

\author{
Donaldo Bello de Souza* \\ Alzira Batalha Alcântara**
}

\section{Resumo}

Este artigo visa à análise da previsão e dos desafios relativos ao acompanhamento e avaliação local de Planos Municipais de Educação, tomando por base os planos pertencentes a dez municípios da Região Metropolitana do Rio de Janeiro, aprovados no período 2001-2012.Pautado na análise de conteúdo desses documentos,constata a preocupação desses planos em sinalizar a participação de diversos atores sociais na sua elaboração, assim como no âmbito da previsão do seu acompanhamento e avaliação sistemáticos, em que pese o fato de não atribuírem centralidade aos CMEs como lócus privilegiadopara a consecução dessas ações.

Palavras-chave: Plano Municipal de Educação (PME). Plano Nacional de Educação (PNE). Acompanhamento e avaliação.

\footnotetext{
* Doutor em Educação pela Universidade Federal do Rio de Janeiro (UFRJ). Professor do Departamento de Estudos de Políticas Públicas, Avaliação e Gestão da Educação da Faculdade de Educação da Universidade do Estado do Rio de Janeiro (UERJ).

** Doutora em Educação pela Universidade Federal Fluminense (UFF). Professora do Departamento de Ciências e Fundamentos da Educação na Faculdade de Educação da Baixada Fluminense (UERJ).
} 


\section{Introdução}

Na segunda metade da década de 1990, a ideia de formulação de um plano de educação coerentemente com o previsto na Constituição Federal (CF) de 1988 (BRASIL, 1988, arts. 211 e 214) e na Lei de Diretrizes e Bases da Educação Nacional (Ldben), Lei n 9.394, de 20 de dezembro de 1996 (BRASIL, 1996, art. $2^{\circ}$ e art. 10, inciso III )- veio a afetar os municípios brasileiros de uma dupla forma: de um lado, no momento em que o Plano Nacional de Educação (PNE) 2001-2010 (BRASIL,2001) foi elaborado, pois pressupôs a participação do conjunto da sociedade brasileira, incluindo, portanto, os espaços locais, e, de outro, quando essas mesmas localidades vieram, assim como os estados, a serem chamadas a transplantar esse plano para a realidade municipal, dando corpo aos Planos Municipais de Educação (PMEs) (BRASIL,2001,art.2º.

Ainda em relação ao PNE 2001-2010, observa-se que a lei que o regulamentou -Lei nº10.172, de 9 de janeiro de 2001 - determinou que a "A União, em articulação com os estados, o Distrito Federal, os municípios e a sociedade civil" (BRASIL, 2001, art. 3º, caput) deveria proceder à avaliações periódicas relativas à implementação deste plano nacional, a partir do "quarto ano de vigência desta Lei” (BRASIL, 2001, art. $3^{\circ}, \S 2^{\circ}$ ), subsídio estratégico e indispensável ao monitoramento do desenvolvimento local das políticas públicas de educação.

Mais recentemente, as ações acima ressurgem como um dos desafios à implantação do novo PNE - Lei n ${ }^{\circ}$ 13.005, de 25 de junho de 2014 (BRASIL, 2014) -, também em esfera infranacional. Na esfera nacional, este plano determina que a execução e "cumprimento de suas metas serão objeto de monitoramento contínuo e de avaliações periódicas" (BRASIL, 2014, art. 5, caput), a serem institucionalmente realizados pelo Ministério da Educação (MEC), pela Comissão de Educação da Câmara dos Deputados, pela Comissão de Educação, Cultura e Esporte do Senado Federal, pelo Conselho Nacional de Educação (CNE) e, ainda, pelo Fórum Nacional de Educação (FNE) (BRASIL, 2014, art. 5', I-IV). No âmbito infranacional, dispõe que "Os sistemas de ensino dos Estados, do Distrito Federal e dos Municípios criarão mecanismos para o acompanhamento local da consecução das metas deste PNE e dos planos previstos no art. $8^{\circ}$ " (BRASIL, 2014, art. $7^{\circ}, \S 3^{\circ}$ ), ou seja, estes entes federados, ao elaborarem, no prazo de um ano, os respectivos Planos Estaduais de Educação (PEEs), o Plano de Educação do Distrito Federal (PEDF) e os PMEs, deverão observar o seu acompanhamento e avaliação em "consonância com as diretrizes, metas e estratégias previstas neste PNE” (BRASIL, 2014, art. $\left.8^{\circ}\right)$. 
Para Kipnis e Algarte (2001), a avaliação de planos de educação é considerada um importante componente do processo de planejamento e, a um só tempo, mecanismo que viabiliza o acompanhamento, análise e julgamento da execução de todas as suas fases. Assim, a avaliação desses planos, ao lado do reconhecimento do seu caráter político, pode privilegiar dimensões normativas e técnicas, considerando, por exemplo, os seus impactos (efetividade), a consecução dos objetivos e as estratégias de implantação (eficácia) e, ainda, as relações entre os seus benefícios e custos financeiros (eficiência)(ARRETCHE, 1998; BELLONI; MAGALHÃES; SOUSA, 2001;COHEN; FRANCO, 1993; DRAIBE, 2001; FARIA, 2005; VIANA, 1996). Em síntese, a avaliação possibilita verificar, com relação ao que foi originalmente traçado, se o plano está gerando as mudanças vislumbradas no planejamento (RAMOS; SCHABBACH, 2012).

Mas a avaliação de uma política, em particular de planos de educação, pode também ocorrer de forma articulada com as ações de monitoramento/acompanhamento da execução do plano, que caracteristicamente se voltam para a verificação sistematizada e processual de sua eficiência e eficácia, possibilitando, com isto, o redirecionamento das decisões (metas e estratégias) previstas (FARIA, 2001; GARCIA, 2001), ou seja, o replanejamento da ação pública (BORDIGNON, 2014).

Entretanto, segundo Dourado (2010, p. 681), a avaliação das políticas públicas, especialmente as de cunho social, vem se constituindo em "um grande desafio para a área educacional, seja em função dos limites teóricos e metodológicos subjacentes ao seu grau de complexidade, pelo envolvimento de diferentes atores ou pelo seu desdobramento abrangente, envolvendo questões que transcendem o escopo da área [...]". Conforme sinalizado por Bonamino et al. (2006, p. 155), soma-se a estes desafios o fato de que no Brasil "não há uma tradição de se valorizar os resultados da avaliação para o planejamento educacional e o destino de grande parte dos relatórios de avaliação, quando produzidos, é o ‘arquivo morto’ das Secretarias de Educação”.

O presente artigo visa analisar a previsão das ações de acompanhamento e avaliação de PMEs e seus desafios, tomando por base empírica os planos pertencentes a 10 (dez) municípios da Região Metropolitana (RM) do Rio de Janeiro ${ }^{1}$, aprovados no período 2001-2012, de modo a contribuir para as reformulações e adequações que o novo PNE (BRASIL, 2014) impõe aos planos locais existentes, assim como para aqueles em vias de elaboração ${ }^{2}$.

Trata-se, portanto, de um estudo de caráter exploratório e de cunho descritivo (KETELE; ROEGIERS, 1993), uma forma de trabalho metodológico das ciências humanas e sociais (LAVILLE; DIONNE, 1999; LESSARD-HÉBERT; GOYETTE; BOUTIN, 2005) que também estabelece incursões 
comparativas (YANG, 2015), relativas não apenas ao PNE mas também aos próprios PMEs. Metodologicamente, encontra-se ancorado na análise de conteúdo, método que visa favorecer a descoberta de "conteúdos e estruturas das mensagens e esclarecer elementos de significações de mecanismos não imediatamente perceptíveis" (BARDIN, 2004, p. 29) a partir do conjunto de elementos que sejam relevantes para o estudo. Adota ainda a análise categorial, tomando em consideração a totalidade de cada documento legislativo, examinando-os e submetendo-os ao "crivo da classificação e do recenseamento, segundo a frequência de presença (ou de ausência) de itens de sentido" (BARDIN, 2004, p. 32, grifos no original), para, em seguida, levar a efeito o processo de deduções lógicas que eles possibilitam ${ }^{3}$.

Além da presente introdução, a segunda seção discute a criação e configuração geral das RMs no Brasil, convergindo para a sua caracterização no âmbito do Rio de Janeiro. Na sequência, traça um panorama acerca dos PMEs dessa RM, também indicando o processo de aprovação e os marcos jurídicos que regulamentam os planos considerados nas análises. Já a quarta seção se volta para o exame descritivo dos princípios, concepções e justificativas relativas à elaboração desses planos, enquanto a quinta seção aborda, sob a mesma perspectiva descritiva, a sua estrutura e dimensões básicas. Finalmente, a sexta seção culmina na análise da previsão propriamente dita do acompanhamento e avaliação nesses/desses PMEs, sucedida pela apresentação dos resultados finais da pesquisa.

\section{Criação e configuração geral das RMs no Brasil e no Rio de Janeiro}

É praticamente consensual que a governança metropolitana consiste em um dos principais problemas do mundo globalizado, entendendo que se trata de cidades ditas intermunicipais, que enfrentam problemas urbanos complexos e, a um só tempo, desafios de gestão conjunta nas mais variadas áreas dos serviços públicos (CARVALHO; PASTERNAK; BOGUS, 2010; LACERDA, 2011; MARICATO, 2000, 2011).

No caso do Brasil, pelo fato de os municípios terem ascendido, com a CF/1988 (BRASIL, 1988), à condição de entes autônomos federados, bem como de ter se tornado mais clara a qualificação das Regiões que poderiam ser dotadas de funções e estruturação tipicamente metropolitanas (HOTZ, 2000), novos desafios surgem para a cooperação intermunicipal, pois, em face do movimento de 
descentralização da gestão dos serviços públicos, a colaboração no interior dessas regiões tende a diminuir os processos de regulação centralizados pelos estados ou pela União (LACERDA, 2011).

Segundo Maricato (2011), há uma precariedade em torno do quadro legal de RMs no Brasil, caracterizada por diferenciações demográficas, econômicas, sociais e políticas decorrentes da pluralidade de critérios adotados para a sua criação entre os estados da federação, a par da incipiente cooperação intermunicipal - esta destacada por Souza (2003) como uma das maiores dificuldades, não apenas atinentes aos municípios, mas ao conjunto das relações entre os entes federados no país - e da prevalência de programas de investimentos esporádicos e de natureza setorial nessas regiões, como os que se voltam, por exemplo, em âmbito federal, para as áreas de habitação e saneamento e, na esfera estadual, para o setor de transportes ${ }^{4}$.

Tais dificuldades vieram no rastro de um processo acelerado de crescimento da população urbana brasileira, entre os anos 1950 e 1970, especialmente devido à expansão do fluxo migratório rural-urbano interno, também impulsionado pela concentração espacial do processo de desenvolvimento industrial no Rio de Janeiro e, sobretudo, em São Paulo. Será nos idos de 1970 que esta expansão urbana ocorrerá em meio à formação das grandes RMs no país (BRITO, 2006). Em 1973, as primeiras dessas regiões vieram a ser implantadas sob base legal e jurídica federal, com a aprovação da Lei Complementar (LC) nº 14, de 8 de junho de 1973 (BRASIL, 1973) - consequência da CF/1967 (BRASIL, 1967) e de sua Emenda Constitucional (EC) $\mathrm{n}^{\circ} 1$ (BRASIL, 1969) -, embora algumas experiências isoladas de administração metropolitana se fizessem notar desde a década de 1960, por iniciativa de alguns governos estaduais (ROLNIK; SOMEKH, 2000) ${ }^{5}$.

Em que pese o fato de o Rio de Janeiro não ter sido contemplado na LC n ${ }^{\circ}$ 14/1973 (BRASIL, 1973), sua RM veio a ser estabelecida por meio da $\mathrm{LC}^{\circ}$ 20, de $1^{\circ}$ de julho de 1974 (BRASIL, 1974), que, no Capítulo II, determinava a fusão dos estados do Rio de Janeiro e da Guanabara. A seção IV, intitulada "Da Região Metropolitana do Rio de Janeiro", em seu art. 19, parágrafo único, estabeleceu como componentes iniciais desse espaço, então delimitado, 14 municípios. Mais adiante, o art. 21 determinava a criação de um fundo contábil para o desenvolvimento da RM do Rio de Janeiro, destinado a financiar programas e projetos prioritários para a região.

$\mathrm{Na}$ atualidade, a RM do Rio de Janeiro é composta por 19 municípios (RIO DE JANEIRO, $2010)^{6}-20,6 \%$ do total de 92 localidades -, sendo considerada, há muitas décadas, uma região em crise, especialmente devido à ausência de dinamismo econômico. Estima-se que o seu Produto Interno Bruto (PIB) esteja em situação de estagnação desde o início dos anos 1980 (RIBEIRO; RODRIGUES; 
CORREA, 2008), ao lado da queda dos indicadores de desenvolvimento humano, marcada pelo aumento do desemprego, queda da renda e aumento da informalidade, que se refletem, portanto, na crescente desigualdade e indigência (URANI et al., 2006).

De acordo com o censo demográfico realizado pelo Instituto Brasileiro de Geografia e Estatística (IBGE) em $2010^{7}$, a população do estado do Rio de Janeiro foi estimada em 15.989.929 habitantes, dos quais 3.375.640 se encontram em idade escolar, apresentando taxas de analfabetismo que variam entre $1 \%$, na faixa etária dos 10 aos 14 anos, e 3,7 \%, na faixa etária a partir dos 15 anos. Dessa população, a maior parte $(74,2 \%)$ está localizada na RM em questão (OBSERVATÓRIO DAS METRÓPOLES, 2011), constituindo-se em um território com alta densidade demográfica e índices de alfabetização entre os piores do país: em toda a região da fronteira metropolitana, assim como nas áreas de favela, há mais de um terço das pessoas com idade superior a 24 anos na condição de analfabetas funcionais (OBSERVATÓRIO DAS METRÓPOLES, 2005).

\section{Processo de elaboração dos PMEs}

Em 2008, apesar de o estado do Rio de Janeiro ainda não possuir o seu $\mathrm{PEE}^{8}$, a Assembleia Legislativa do Estado do Rio de Janeiro (Alerj), por meio de sua Comissão de Educação, buscou conduzir os municípios fluminenses à elaboração dos seus PMEs. Para tanto, promulgou a Lei n ${ }^{\circ} 5.332$, de 24 de novembro de 2008, prevendo a suspensão de transferências de receitas próprias do estado, "respeitando os limites constitucionais legais" (RIO DE JANEIRO, 2008, art. $1^{\circ}$ ), para localidades que, até 2010, não tivessem elaborado o seu respectivo plano, com aprovação pela Câmara Municipal.

De acordo com Vale, Menezes e Vasconcelos (2010), pelas informações encaminhadas pelas Secretarias Municipais de Educação (SMEs) à Comissão de Educação da Alerj, já no início de 2009, apenas 30\% (28) dos 92 municípios do estado possuíam PME sob a forma de Lei Municipal. A justificativa apresentada pelos demais municípios se referia, especialmente, à espera pelo PEE, apesar de essas instâncias terem autonomia para planejar suas próprias políticas educacionais. De acordo com Vasconcelos, Peixoto e Vidal (2012), cujo levantamento tomou por base informações da Comissão de Educação da Alerj, em 2011 este quadro havia evoluído para não mais do que 52\% (48) das localidades fluminenses com PME aprovado por lei, correspondendo a 23 PMEs a menos do total declarado pelos municípios fluminenses para a Pesquisa de Informações Básicas Municipais (MUNIC), realizada pelo IBGE, relativa ao ano de 2011 (IBGE, 2012). 
Contudo, em dezembro de 2012, após amplo e exaustivo levantamento documental ${ }^{9}$, os autores do presente texto lograram localizar, única e exclusivamente, 33 PMEs e suas respectivas leis, aprovados, na sua quase totalidade, ao longo do período de vigência do PNE 2001-2010, correspondentes a $36 \%$ dos 92 municípios do estado, neste caso, 38 planos a menos do que fora apresentado ao MUNIC/IBGE (71) (IBGE, 2012) e 15 a menos do total de planos cujas leis constavam nos registros da Alerj (VASCONCELOS; PEIXOTO; VIDAL, 2012).

Daquele universo de 33 PMEs localizados por estes autores ${ }^{10}$, verificou-se que somente 10 pertenciam a municípios da RM do Rio de Janeiro, expressão de 53\% do total de 19 localidades que compõem esta região, a saber: Itaboraí (2008a; 2008b), Japeri (2008a; 2008b), Maricá (2008), Nilópolis (2001a; 2001b), Niterói (2010; 2008), Queimados (2009a; 2009b), Rio de Janeiro (2008a; 2008b), São Gonçalo (2006a; 2006b; 2006c), Seropédica (2011; 2012) e Tanguá (2009a; 2009b), a seguir examinados.

Se apenas 10 (53\%) dos 19 municípios que integram a RM do Rio de Janeiro possuem PMEs (isto até dezembro de 2012), também é possível afirmar, com base nos dados do Quadro 1, que o movimento para a elaboração de seus respectivos planos não ocorreu de forma imediata à aprovação do PNE 2001-2010 (BRASIL, 2001). Afinal, desses 10 planos, somente Nilópolis elaborou e aprovou o seu em 2001, ou seja, no mesmo ano em que aquele plano nacional veio a ser regulamentado por lei. Com exceção de Nilópolis, os demais municípios aprovaram seus respectivos planos a partir do sexto ano de vigência do PNE em questão: São Gonçalo, em 2006; Itaboraí, Japeri, Maricá, Niterói e Rio de Janeiro, em 2008; Queimados e Tanguá, em 2009, e Seropédica, quando a validade do PNE já havia expirado, em 2012. Vale observar que a maioria não explicita o período de vigência do plano; logo, deduz-se que iniciaram a partir da data da sua aprovação.

\section{Quadro 1}

Leis, datas de aprovação e vigências dos PMEs da RM do Rio de Janeiro

\begin{tabular}{|l|r|r|l|}
\hline \multicolumn{1}{|c|}{ Município } & Lei $n$ o & Data da aprovação & \multicolumn{1}{c|}{ Vigência } \\
\hline Itaboraí & 2.077 & $28 / 11 / 2008$ & $2008-2017^{* *}$ \\
\hline Japeri & 1.155 & $10 / 04 / 2008$ & $2008-2018^{*}$ \\
\hline Maricá & 2.281 & $19 / 12 / 2008$ & $2008-2017^{* *}$ \\
\hline Nilópolis & 5.982 & $13 / 12 / 2001$ & $2002-2011^{*}$ \\
\hline Niterói & 2.610 & $31 / 10 / 2008$ & $2008-2017^{* *}$ \\
\hline Queimados & 972 & $24 / 12 / 2009$ & $2009-2019^{*}$ \\
\hline Rio de Janeiro & 4.866 & $02 / 07 / 2008$ & $2008-2017^{* *}$ \\
\hline
\end{tabular}




\begin{tabular}{|l|r|r|l|}
\hline São Gonçalo & 56 & $01 / 08 / 2006$ & $2006-2015^{* *}$ \\
\hline Seropédica & 426 & $02 / 01 / 2012$ & $2012-2022^{*}$ \\
\hline Tanguá & 717 & $24 / 11 / 2009$ & $2009-2018^{* *}$ \\
\hline
\end{tabular}

FONTE: Os autores.

* Período de vigência está explicitado no documento do PME ou na lei correspondente.

** Período de vigência não consta explicitado no PME, tampouco na lei correspondente, tendo sido deduzido a partir da sua data de aprovação, tendo por base a lógica adotada no PNE 2001-2010 (BRASIL, 2001). Vale notar que não há um critério padronizado no que tange à duração nos planos investigados, pois alguns extrapolam o período decenal.

No processo de construção do PME, os 10 municípios ressaltaram que houve participação da sociedade civil, ainda que alguns não tenham explicitado quais os principais atores sociais envolvidos e sequer a forma como ocorreu esse processo, atendo-se a uma descrição genérica que não auxilia na tarefa de qualificação desse processo supostamente participativo. Todavia importa notar que o CME, espaço privilegiado para uma construção coletiva e democrática da gestão educacional, foi citado em todos os planos, mas apenas em 5 deles - Japeri, Niterói, Rio de Janeiro, São Gonçalo e Seropédica assumiu papel de maior destaque, cumprindo distintas funções, como elaboração, análise e sistematização do documento final e/ou coordenação de todo o processo de sua elaboração. Nos demais, o CME assume tarefas pontuais, como ocorreu no município de Maricá, embora conste que tenha elaborado o PME. Em outros, o CME é evocado após a conclusão da elaboração do plano, seja para assumir a responsabilidade de criar mecanismos voltados para o seu acompanhamento, como ocorreu no PME de Queimados e Tanguá, ou para fins de apreciação do plano já finalizado, como se deu em Nilópolis. Em Itaboraí, o CME possuiu representante na Conferência Municipal, mas não aparece como protagonista da elaboração do PME.

A forma privilegiada para a construção do plano ocorreu por meio de encontros, reuniões e seminários, e 4 municípios - Itaboraí, Niterói, Queimados e Seropédica - destacaram a realização de Conferência Municipal de Educação como marco para a elaboração do plano. Niterói, além de conferências, instalou um Fórum Municipal de Educação como estratégia para elaboração do plano; Japeri optou pelos fóruns temáticos realizados nas escolas, enquanto Nilópolis destacou o papel proeminente da SME na construção do plano, seja convocando as escolas para debater, seja instituindo uma equipe para redigir o plano, cabendo ao CME a tarefa de analisá-lo. No Rio de Janeiro, o CME coordenou o processo de construção do plano, que teve como ponto inicial a realização de um grande seminário na Câmara dos Vereadores. Buscou-se o diálogo com autoridades educacionais dos diferentes níveis, além de representantes desta enorme rede municipal, por meio de Conselhos eleitos nos diversos segmentos da comunidade escolar. Em São Gonçalo, a SME não só organizou fóruns 
temáticos, nos quais foram estabelecidas as metas do plano, como também foi responsável pela redação do documento final submetido à análise do CME. Entretanto nem sempre os planos analisados expressam como foi realizada a dinâmica desses encontros, ou seja, o processo é descrito de forma bastante vaga, sem detalhamentos sobre o número de encontros realizados nem descrição pormenorizada de como ocorreu o processo de discussão em si. Maricá e Tanguá ilustram tal situação.

O tempo dedicado para a elaboração do plano também não foi uniforme, pois 4 PMEs levaram cerca de um ano para serem concluídos - Itaboraí, Rio de Janeiro, Japeri e Seropédica -, ao passo que Nilópolis e Queimados consumiram, respectivamente, 6 e 3 meses entre discussão, elaboração e aprovação do plano. Já Niterói e São Gonçalo tiveram um processo de debate e elaboração mais demorado. O primeiro discutiu e teceu o seu plano entre os anos de 2003 e 2007, aprovando-o no ano seguinte, enquanto São Gonçalo o elaborou entre 2003 e 2006, tendo a sua aprovação ocorrido ainda em $2006^{11}$. Vale notar que nem sempre o plano é aprovado logo após a sua finalização, como ocorreu no Rio de Janeiro, cujo processo centrou-se entre novembro de 2003 e outubro de 2004, mas sua aprovação só se efetivou em julho de 2008.

Embora todos os documentos analisados tenham valorizado, com ênfases diferenciadas, a participação coletiva na edificação do PME, este processo não foi uniforme. Vale destacar, a título de exemplificação dessa diversidade, dois municípios - Japeri e Nilópolis -, que elegeram a unidade escolar como espaço de discussão, mas tiveram dinâmicas próprias. Japeri sinaliza que a revitalização do CME foi o marco inicial, sendo constituídos uma comissão e diversos grupos de trabalhos, que debateram os referenciais teóricos e delinearam uma proposta. Fóruns temáticos foram realizados ao longo de um mês em todas as unidades escolares, e as considerações feitas a partir desses fóruns foram encaminhadas para a SME, que buscou sistematizá-las. A SME, ao perceber a necessidade de aprofundar o conhecimento sobre a realidade municipal, realizou um minicenso educacional envolvendo o conjunto das escolas e a comunidade em geral. Após analisar todos os dados, a comissão sistematizou uma primeira versão, que foi enviada às escolas para apreciação e elaboração de novas considerações. É possível perceber um movimento de idas e vindas que sugere a valorização de um coletivo centrado nos educadores. Em Nilópolis, também ocorreram reuniões nas unidades escolares, mas, ao que tudo indica, a dinâmica foi distinta. A SME convocou todos os segmentos da comunidade escolar para elaborar sugestões, no prazo de uma semana, a fim de viabilizar o "Dia da Parada Obrigatória para o Plano Municipal de Educação". Com o objetivo anunciado de estimular a participação, uma comitiva liderada pelo Prefeito e composta pelo Secretário Municipal e por membros 
do legislativo percorreu todas as escolas no dia previsto para a "Parada Obrigatória". O material produzido foi enviado à SME, que, por meio de uma equipe, ficou responsável pela "seleção final do que viesse a fazer-se viável" para ser contemplado no plano (NILÓPOLIS, 2001a, p. 4). Embora o plano anuncie uma preocupação em ouvir a comunidade escolar, a dinâmica sugere uma participação de cunho formal, em detrimento de uma escuta que privilegiasse uma pluralidade de vozes.

\section{Princípios, concepções e justificativas dos PMEs}

Se o cumprimento de uma determinação legal - Lei no 10.172/2001 (BRASIL, 2001) - foi o elemento impulsionador para alguns municípios, a busca por uma educação de qualidade e comprometida com as necessidades da população local foi o objetivo mais amplamente destacado, praticamente consensual, como fundamento para a elaboração dos PMEs em questão, ainda que com tons, fins e matizes diferenciados. Tal fato é perceptível no confronto entre as concepções expostas nos respectivos planos. Para Japeri (2008b, p. 40, grifo no original), "as visões que subjazem a este Plano indicam seu referencial maior: mudar o modelo social vigente, transformar a sociedade, tornando-a de fato democrática", enquanto para Maricá (2008, p. 3) a elaboração do PME, "mais do que uma exigência legal e necessária aos sistemas educacionais, é antes de tudo uma oportunidade de fazermos uma declaração de amor e esperança para os nossos educandos". Salta aos olhos o tom mais político expresso no plano de Japeri, com um viés salvacionista, pois o plano tem como referencial maior mudar o "modelo social vigente" (JAPERI, 2008b, p. 40), enquanto o plano de Maricá (2008) prioriza uma retórica de cunho humanista em detrimento da ação política propriamente dita, enfatizando a necessidade de se criar um ambiente em que todos se sintam bem. Para tanto, é essencial a capacidade de educar com amor, ou seja, a comunidade escolar deve estar imbuída desse espírito, pois o "sucesso ou o fracasso de um sistema social é decorrente das ações de seus componentes” (MARICÁ, 2008, p.14).

Se os planos analisados ressaltam que o objetivo precípuo é a construção de uma educação com qualidade, o princípio da gestão democrática também se faz presente no conjunto dos fins anunciados, embora com menor força. Seropédica, por exemplo, explicita a importância da qualidade e da gestão democrática enquanto fins, ao afirmar que o "Plano Municipal de Educação consubstancia os princípios constitucionais da gestão democrática e da qualidade da educação com equidade social, colocando-os como dois grandes desafios para a sociedade brasileira na atual década" (SEROPÉDICA, 2011, p. 11). 
Contudo importa frisar que os planos não indicam de forma mais precisa a concepção de qualidade e de gestão democrática a que aludem, isto é, de forma geral, observa-se ausência de qualificação para esses termos - decerto, polissêmicos -, tendo limitado-se a exprimir uma referência genérica que sinaliza quer a excelência da educação, quer o envolvimento de todos, professores e comunidade, na consecução dos projetos pedagógicos. Tal lacuna pode sugerir que sua inclusão tenha sido feita para evidenciar uma sintonia entre o plano local e os princípios legais mais amplos, que prescrevem relações entre a qualidade e a gestão democrática no ensino público.

Considerando que, historicamente, o campo da política educacional no Brasil tem sido marcado por ações pontuais e fragmentadas, que espelham as prioridades de um dado governo, não é tarefa simples efetivar um sistema de ensino mais orgânico e de larga duração, embora há muito evocado pelos educadores. Em outras palavras, construir uma política com fins e princípios mais amplos, comprometidos com os interesses da maioria da sociedade, requer a implantação de projetos que transcendam a um mandato de governo, o que implica a instauração de uma nova cultura política. Neste sentido, é de grande relevância que a maioria dos planos ${ }^{12}$ ora analisados tenha explicitado, ainda que com formas e termos diferenciados, que o PME consiste em uma política de Estado, e não de governo.

Dentro desta perspectiva, Queimados (2009b, p. 21) afirma que o "Plano Municipal de Educação deve ser um documento comprometido com o futuro da cidade, com o desenvolvimento social, cultural, intelectual e com a qualidade de vida de seus munícipes e, como tal, deve transcender aos governos eleitos". Com objetivo similar, Nilópolis (2001a, p. 21) anuncia que "os objetivos e as metas deste plano transcendem o Plano de Governo". Tanguá, ao relacionar a elaboração do plano local à determinação expressa na Lei no 10.172/2001 (BRASIL, 2001), enfatiza que se trata de um "plano municipal e não de um plano governamental" (TANGUÁ, 2009b, p. 9). Japeri (2008b, p. 87), ao tratar dos objetivos e metas do seu plano, afirma que "somente poderão ser alcançados se ele for concebido e acolhido como um Plano de Estado, mais do que como um Plano de Governo, e por isso, assumido como um compromisso da sociedade para consigo mesma". O mesmo princípio está exposto no plano do Rio de Janeiro (2008b, p. 79) - aliás, com redação muito similar -, ao afirmar que seus objetivos e metas "somente serão alcançados se o Plano for reconhecido como Plano de Estado, mais do que um plano de governo, assumido como um compromisso da sociedade para consigo mesma". Um plano cuja periodicidade é decenal traça objetivos, metas e ações que vão muito além de um governo em si. Assim, sua natureza pode assegurar a continuidade de uma política educacional, como expressaram os planos de São Gonçalo e Seropédica, o que é fundamental para se conquistar a qualidade educacional. 
Importa ressaltar uma finalidade apontada no PME de Itaboraí, dada sua relevância no campo da política. Além de elencar os objetivos mais amplos e as prioridades municipais para a educação, o plano pode servir como mecanismo para a efetivação do próprio regime de colaboração previsto constitucionalmente, mas, até o momento, ainda não regulamentado (ARAÚJO, 2013). Afinal, no PME de Itaboraí destaca-se que este deve "funcionar como ferramenta para articular as ações entre as instâncias federal, estadual e municipal” (ITABORAÍ, 2008b, p. 2).

\section{Estrutura e dimensões básicas dos PMEs}

Cumpre inicialmente sinalizar que um PME apresenta, de forma geral, uma estrutura que contempla: introdução, caracterização do município, diagnósticos, diretrizes, objetivos/metas e ações concernentes a distintos eixos, além de uma parte dedicada ao acompanhamento e avaliação do plano. Ou seja, cada PME atribui aos níveis, às modalidades de ensino, à formação e à valorização do magistério, como também ao campo do financiamento e gestão da educação, objetivos/metas que devem ser alcançados por meio de ações/estratégias em um determinado prazo (BONAMINO et al., 2006; MONLEVADE, 2002; ROCHA; MONLEVADE; AGUIAR, 2006).

No que concerne aos PMEs em tela, constata-se que a sua extensão é bastante diferenciada, o que, em parte, traduz-se na presença de maior detalhamento sobre algumas informações ou de um debate mais prolongado sobre certos temas em alguns planos, enquanto os planos mais sintéticos, via de regra, expõem um tom mais lacônico e genérico.

A parte introdutória desses PMEs revela, de certa forma, o perfil do próprio plano. Alguns tecem um debate de natureza mais política sobre o papel de um PME, buscando inclusive situá-lo no contexto maior da organização educacional, ou seja, estabelecem uma discussão que transborda as fronteiras municipais, reconhecendo não só a vitalidade de um PME na construção de uma política de Estado mas também sua relevância para o desafio de construir uma gestão democrática (JAPERI, 2008b; QUEIMADOS, 2009b; RIO DE JANEIRO, 2008b; SÃO GONÇALO, 2006c; TANGUÁ, 2009b). Em outros, todavia, nota-se uma introdução de caráter mais formal, em que tais debates foram secundarizados ou estão ausentes (MARICÁ, 2008; NITEROI, 2008).

A elaboração de um diagnóstico é etapa estratégica para o processo de construção de um planejamento, pois consiste no exame da situação de cada eixo temático do plano por meio da análise de dados quantitativos e de caracterizações e contextualizações qualitativas, compreendendo a 
especificação de problemas, dificuldades e perspectivas de uma dada realidade educacional (BONAMINO et al., 2006; MONLEVADE, 2002). Importa realçar que, embora a maioria dos PMEs ora analisados tenha apresentado seção relativa ao diagnóstico, ainda que de formas distintas, nem sempre esta etapa ocupou um lugar de maior destaque. Assim, o diagnóstico apresentou, de forma recorrente, um caráter vago, pois prioriza considerações de âmbito nacional, princípios expressos na LDBEN n 9.394/1996 (BRASIL, 1996) ou perpassa problemas clássicos que marcam a educação no país, apoiando-se, sobretudo, em dados educacionais mais gerais e genéricos, como expressam, por exemplo, os planos de Itaboraí, Maricá, Nilópolis, Rio de Janeiro, São Gonçalo e Tanguá, com exceção dos aspectos históricos mais amplos de cada localidade, bem como da trajetória educacional do município, seja abordando o nível ou a modalidade de ensino.

Em contrapartida, Japeri, Queimados e Seropédica evidenciam um maior empenho em traçar diagnósticos que deem conta da realidade educacional local, não se atendo aos dados mais gerais. Queimados (2009b, p. 7) registrou que de "todas as dificuldades para a elaboração do PME, certamente a pesquisa diagnóstica foi a maior". Ressalta a importância de se conhecer detalhadamente os recursos disponíveis (humanos e financeiros), bem como as potencialidades e necessidades educacionais locais. Japeri teve uma posição similar, pois parte do princípio de que a deliberação de políticas públicas na área educacional requer conhecimento da realidade. Para tanto, a Secretaria Municipal de Educação e Cultura de Japeri realizou um minicenso educacional envolvendo as escolas e a comunidade. Tal minicenso objetivou "identificar a situação de escolarização da população residente no município; construir subsídios para a formulação e avaliação de políticas públicas educacionais; compreender a dinâmica educacional praticada e a educação oferecida" (JAPERI, 2008b, p. 29). Este mecanismo ganha ainda mais relevância ao se perceber a concepção de planejamento que subsidiou a elaboração do PME em questão. Um planejamento deve iniciar "com a tomada de consciência da situação a ser trabalhada. Para tanto, se faz necessário o levantamento de dados significativos da realidade que se constituiu na sondagem desencadeadora da reflexão, diagnóstico e tomada de decisão" (JAPERI, 2008b, p. 39). Seropédica, antes de listar os eixos e metas, contextualiza a educação local e apresenta vários gráficos que buscam indicar a evolução das matrículas em seus diferentes níveis e modalidades. Para tanto, entrelaçou os dados fornecidos pelo Departamento de Ensino da Secretaria de Educação de Seropédica com as "observações diretas e indiretas em visitas sistemáticas realizadas nas escolas da rede" (SEROPÉDICA, 2011, p.12). 


\section{Acompanhamento e avaliação dos PMEs}

Assim como no PNE 2001-2010 (BRASIL, 2001), todos os PMEs em tela dedicam seção específica nos seus respectivos documentos à temática do acompanhamento e avaliação do plano alguns discutindo-as genericamente, enquanto outros apresentam metas/objetivos específicos a serem perseguidos -, ratificando a sua importância no próprio texto da lei que os regulamenta.

Parece haver certo consenso entre os PMEs da RM do Rio de Janeiro sobre o acompanhamento e a avaliação sistemáticos consistirem em subsídio estratégico indispensável ao monitoramento do desenvolvimento local das políticas públicas de educação ${ }^{13}$, pois, tendo em vista que se trata de um plano para dez anos, "por si só já exige cautela e avaliação” (MARICÁ, 2008, p. 13), de modo a: "garantir a efetiva execução dos objetivos e metas" (ITABORAÍ, 2008, p. 125), atribuir-lhe "segurança no prosseguimento das ações ao longo do tempo" (SÃO GONÇALO, 2006c, p. 9), promover "adaptações e medidas corretivas" de percurso (JAPERI, 2008b, p. 87) e balizar "tomada de decisões sempre que o redirecionamento das ações se fizer necessário” (RIO DE JANEIRO, 2008b, p. 78), realimentando a "dinâmica do próprio processo" (TANGUÁ, 2009b, p. 124), isto tudo em sintonia com as "mudanças da realidade social, econômica e educacional do sistema" (SEROPÉDICA, 2011, p. 41), aferidas por meio da "elaboração de constantes diagnósticos” (NILÓPOLIS, 2001a, p. 21).

Assim, a maior parte dos PMEs em tela prevê a realização de avaliações periódicas ${ }^{14}$, no entanto apenas os planos de Nilópolis e Queimados definem periodicidade similar à indicada pelo PNE 2001-2010, qual seja, quadrienal. Já Itaboraí e Niterói determinam periodicidade trienal, enquanto os demais planos - Japeri, Rio de Janeiro, São Gonçalo e Seropédica - optaram por avaliações bianuais, temporalidade à qual atribuem maior produtividade, no tocante a este tipo de planejamento educacional, pois permite, no espaço de dez anos, maior número de intervenções, embora demande, em tempos mais reduzidos, maior atenção sobre o acompanhamento da implantação do plano por parte do poder público e da sociedade civil local.

Do ponto de vista dos espaços institucionais destinados à realização das ações de acompanhamento e avaliação dos PMEs, quase todos os planos sob análise salientam o papel da Câmara Municipal de Vereadores ${ }^{15}$, reiterando sua competência para aprovação de medidas que, apoiadas nos resultados dessas avaliações, visem a novos ajustes das metas e objetivos previstos, assim como eventuais correções e distorções no seu desenvolvimento. 
Alguns planos responsabilizam diretamente a SME pelas avaliações da implementação do PME, o que deve ser feito de modo articulado com o CME e "todas as entidades sociais que tenham legítimo interesse no desenvolvimento de uma educação de qualidade no Município" (NILÓPOLIS, 2001a, p. 21), ou sinalizam que o "melhor segmento de acompanhamento e avaliação do Plano é a própria sociedade, por meio da organização de seus atores, sejam eles governamentais ou não [...]" (TANGUÁ, 2009b, p. 124). Outros planos deslocam essa centralidade da SME para o CME (ITABORAÍ, 2008, JAPERI, 2008b; NITERÓI, 2008; RIO DE JANEIRO, 2008b; SÃO GONÇALO, 2006c; QUEIMADOS, 2009b), embora reconhecendo a importância do papel indutor da SME no desenvolvimento do PME.

A um só tempo, determinadas localidades buscam também instituir espaços e modos específicos para o acompanhamento e avaliação dos seus respectivos PMEs, como, por exemplo, a criação, pelo CME, de um Núcleo Municipal de Acompanhamento e Avaliação do PME (ITABORAÍ, 2008), de um Fórum Permanente de Acompanhamento e Avaliação do PME (SEROPÉDICA, 2011), ou mesmo a constituição de um Sistema Municipal de Avaliação coordenado pelo CME (NITERÓI, 2008; RIO DE JANEIRO, 2008b) ou pela SME (NILÓPOLIS, 2001b), todos eles compostos por representação de diversos segmentos do poder público e da sociedade civil ${ }^{16}$.

Quanto aos instrumentos que viabilizarão as ações de acompanhamento e avaliação desses PMEs, nota-se que metade dos planos não se furta a mencioná-los ${ }^{17}$, quer, de modo mais genérico, indicando que devem estar apoiados em dados e análises quantitativas e qualitativas de âmbito federal, estadual e/ou municipal (JAPERI, 2008b; MARICÁ, 2008; RIO DE JANEIRO, 2008a, 2008b), quer nomeando-os, como no caso dos indicadores da Avaliação Nacional da Educação Básica (Aneb) - um dos processos avaliativos compreendido pelo Sistema Nacional de Avaliação da Educação Básica (Saeb) -, do Exame Nacional do Ensino Médio (Enem), do Exame Nacional de Desempenho dos Estudantes (Enade) ou, ainda, dos dados censitários produzidos pelo Instituto Nacional de Estudos e Pesquisas Educacionais Anísio Teixeira (INEP) e pelo IBGE (ITABORAÍ, 2008; NILÓPOLIS, 2001a; QUEIMADOS, 2009b).

Finalmente, cabe destacar que somente os documentos de Niterói (2008, 2010b) apontam mecanismos e procedimentos voltados à publicização local do PME, especialmente quando preveem a sua publicação "em forma de livreto, com distribuição gratuita nos diversos setores da sociedade" (NITERÓI, 2010b, p. 20), embora Nilópolis, Queimados e Rio de Janeiro, de forma genérica, ressaltem que o poder público local deverá empenhar-se na divulgação dos seus respectivos PMEs e dos 
resultados das avaliações levadas contínua e periodicamente a efeito, de modo que a sociedade o conheça e acompanhe sua implementação, contudo sem indicar os instrumentos a serem empregados.

\section{Considerações finais}

À guisa de conclusão, cabe inicialmente destacar as dificuldades enfrentadas pelos autores deste texto e sua equipe de pesquisa ao longo do processo de levantamento dos PMEs relativos ao estado do Rio de Janeiro, e não apenas à sua RM, quer em função do desencontro de informações entre os órgãos oficiais nacionais e locais e as pesquisas acadêmico-científicas, quer em razão das adversidades que marcaram o acesso aos documentos caracterizadores desses PMEs (leis e planos propriamente ditos). Em larga medida, tais tribulações evidenciam desafios ainda não superados pela dita Administração Pública moderna no país, com efeitos negativos para o processo de fortalecimento da democracia, já que, entre outros aspectos, obstaculizam a transparência pública e, por conseguinte, o controle social de políticas como, neste caso, as concernentes ao planejamento educacional.

As análises até aqui realizadas enfocaram PMEs da RM do Rio de Janeiro que, na sua quase totalidade, vieram a ser aprovados, por lei ordinária, já em fins da vigência do PNE 2001-2010 (majoritariamente em 2008), o que significa que, levando em conta a inércia de sua implantação pósaprovação legislativa, presumidamente, devem ter proporcionado pouca ou nenhuma contribuição efetiva à materialização local dos objetivos e metas daquele plano nacional, já que passaram a vigorar no mesmo período em que o PNE 2001-2010 alcançava o seu fim. Transcorrida cerca da metade do tempo de vigência da maior parte desses planos, os municípios em questão passam a enfrentar novos desafios, em razão da necessidade de reformulá-los e adequá-los ao novo PNE, aprovado em 25 de junho de 2014.

No seu conjunto, os PMEs em causa apresentam elementos que nos autorizam a afirmar que a sua elaboração contou com a ampla participação de diversos atores sociais locais em encontros, reuniões e seminários, mas não necessariamente com o protagonismo por parte do CME, lócus privilegiado pelo seu potencial democrático, entre outras competências e atribuições afetas a esta finalidade. Conforme depreendido das análises, o papel desempenhado por este órgão colegiado durante a elaboração desses planos não encontra uniformidade entre os municípios em questão, podendo abarcar ações relativas à sua sistematização, apreciação e acompanhamento, mas apenas em 
alguns casos engloba a coordenação do processo de sua elaboração propriamente dita que, tipicamente, sugere-se que seja centralizado pela SME.

De modo unânime, os PMEs estudados sinalizam a importância do seu acompanhamento e avaliação sistemáticos, articulados ao cumprimento dos objetivos e metas do plano, em períodos que, dependendo do município, variam de dois a quatro anos. Apesar de consensualmente apontarem a Câmara Municipal de Vereadores como espaço institucional destinado a esta finalidade, reconhecendo, portanto, o papel deliberativo do Poder Legislativo local em torno dos ajustes processualmente demandados pela operacionalização dos PMEs, esses planos entendem que a responsabilidade pelo seu acompanhamento e avaliação concerne, de fato, aos Sistemas Municipais de Ensino.

Assim, do mesmo modo que ocorre com a elaboração desses PMEs, a centralidade do seu acompanhamento e avaliação, embora contextualizada na esfera do Sistema Municipal de Ensino, não se encontra necessariamente posta no CME, lócus privilegiado de participação sociopolítica, podendo constituir-se também em prerrogativa da SME, sendo poucos os destaques observados em relação à importância da participação sociopolítica nesse processo.

Por se tratar, em tese, de espaços de participação sociopolítica, com representação do poder público e da sociedade civil organizada, não se pode perder de vista que, potencialmente, os CMEs tendem a garantir não apenas a qualidade técnica deste importante instrumento de planejamento da educação local, passível de ocorrer também por meio das SMEs, mas, especialmente, sua qualidade social. Quer em função da regularidade de realização das suas reuniões, quer em decorrência do conjunto amplo de competências/funções que institucionalmente abarcam, a começar pela fiscalizadora, os CMEs levam a crer que técnica e politicamente podem contribuir sobremaneira para a consolidação de um planejamento local da educação de matriz democrática e descentralizada - mesmo considerando a interdependência destas duas dimensões -, de forma coesa com as políticas de Estado, como no caso dos PMEs, reconhecimento que, decerto, depende do grau da correlação de forças sociais do município, ou seja, de sua maturação político-democrática.

Conclusivamente, postula-se que, do ponto de vista documental, os PMEs estudados não se furtaram a prever o seu acompanhamento e avaliação, com distintas estratégias e em espaços institucionais diferenciados, restando saber se, em termos práticos, a implementação desses planos veio a ser, de fato, retroalimentada pelos resultados dessas ações avaliativas, questão que extrapola os limites do presente estudo. 


\section{Notas}

${ }^{1}$ Essas localidades são mais adiante indicadas.

${ }^{2}$ Devido a delimitações metodológicas, os novos PMEs metropolitanos doRio de Janeiro, alinhados ao PNE 20142024, não fazem parte do objeto deste estudo, e também porque, no momento de sua finalização, em julho de 2014 , a elaboração e/ou atualização desses planos sequer havia principiado. De qualquer modo, cabe salientar que esses novos planos serão oportunamente examinados por estes mesmos autores.

${ }^{3}$ Este estudo é um dos subprodutos do projeto de pesquisa denominado "Os Planos Municipais de Educação (Brasil) e as Cartas Educativas Municipais (Portugal): perspectiva comparada entre as Regiões/Áreas Metropolitanas do Rio de Janeiro e do Porto", realizado pelo Núcleo de Estudos em Política e História da Educação Municipal (Nephem) da Faculdade de Educação da Universidade do Estado do Rio de Janeiro (Uerj) em conjunto com o Centro de Investigação e Inovação em Educação (InEd) da Escola Superior de Educação (ESE) do Instituto Politécnico do Porto (IPPorto), sob coordenação, no Brasil, do Prof. Dr. Donaldo Bello de Souza e, em Portugal, da Prof. ${ }^{a}$ Dr. ${ }^{a}$ Dora Fonseca Castro (SOUZA; CASTRO, 2011).

${ }^{4}$ Em 2010 o país possuía 35 RMs, compostas por 444 municípios, distribuídos entre 21 estados, além do Distrito Federal (DF), acrescidos de três Regiões Integradas de Desenvolvimento Econômico (Rides) que abrangem mais de um estado (MARICATO, 2011).

${ }^{5}$ Nesta época, foram criadas áreas metropolitanas nas capitais: São Paulo, Porto Alegre, Belém, Salvador e Belo Horizonte (ROLNIK; SOMEKH, 2000).

${ }^{6}$ A saber: Belford Roxo, Duque de Caxias, Guapimirim, Itaboraí, Itaguaí, Japeri, Magé, Maricá, Mesquita, Nilópolis, Niterói, Nova Iguaçu, Paracambi, Queimados, Rio de Janeiro, São Gonçalo, São João de Meriti, Seropédica e Tanguá (RIO DE JANEIRO, 2010).

${ }^{7}$ Disponível em: <http://censo2010.ibge.gov.br/resultados>. Acesso em: 16 set. 2011.

${ }^{8} \mathrm{O}$ estado do Rio de Janeiro veio a ter o seu PEE aprovado somente no nono ano de vigência do PNE 2001-2010 (BRASIL, 2001), ou seja, às vésperas do seu término, quando, pela Lei no 5.597, de 18 de dezembro de 2009 (RIO DE JANEIRO, 2009a; 2009b) atendeu ao que fora previsto no inciso III do art. 10 da LDBEN $\mathrm{n}^{\circ} 9.394 / 1996$ (BRASIL, 1996), a saber, que os estados deveriam incumbir-se de "elaborar e executar políticas e planos educacionais, em consonância com as diretrizes e planos nacionais de educação, integrando e coordenando as suas ações e as dos seus Municípios”, tarefa iniciada no ano de 2002, por ocasião da constituição, pela Secretaria de Estado de Educação (Seeduc), da comissão inicialmente responsável por sua elaboração (VALE; MENEZES; VASCONCELOS, 2010).

${ }^{9}$ Ao longo dos anos 2011 e 2012, para a realização do levantamento dos PMEs do Rio de Janeiro, foram adotados por estes autores e seus colaboradores três procedimentos básicos: i) consulta via internet aos sítios relativos aos municípios - Prefeitura Municipal, SME, CME e Câmara Municipal -, assim como a diversas bases de dados disponíveis nesta rede; ii) consulta in loco ao setor de arquivo relativo à Comissão de Educação da Alerj; iii) contato telefônico junto às SMEs e aos CMEs dessas localidades.

${ }^{10}$ Além dos 10 PMEs referentes aos municípios da RM do Rio de Janeiro, registraram-se outros 23 planos concernentes às seguintes localidades: Cabo Frio, Rio Bonito, Angra dos Reis, Mangaratiba, Campos dos Goytacazes, Conceição de Macabu, Macaé, São Fidélis, São João da Barra, Italva, Itaperuna, Santo Antonio de Pádua, Nova Friburgo, Petrópolis, Areal, Mendes, Miguel Pereira, Paraíba do Sul, Vassouras, Barra do Piraí, Resende, Rio Claro e Rio das Flores.

${ }^{11}$ Não foram identificados, nos documentos relativos aos PMEs de Maricá (2008) e Tanguá (2009a, 2009b), dados sobre o período dedicado à elaboração dos seus respectivos planos.

${ }^{12}$ Não constam, nos documentos relativos aos PMEs de Maricá (2008) e Niterói (2010b), dados explícitos sobre a concepção de um PME enquanto política de Estado, como nos demais planos analisados.

${ }^{13}$ Não foram identificados, nos documentos relativos aos PMEs de Niterói (2008, 2010) e Queimados (2009a, 2009b), elementos explícitos sobre concepções ou princípios concernentes à questão do acompanhamento e avaliação desses planos.

${ }^{14}$ Não foram identificadas, nos documentos relativos aos PMEs Maricá (2008, 2011) e Tanguá (2009a, 2009b), informações a respeito da periodicidade prevista para a realização das avaliações.

${ }^{15}$ Não foram identificadas, nos documentos relativos aos PMEs de Maricá (2008, 2011) e Tanguá (2009a, 2009b), informações a respeito do papel da Câmara Municipal de Vereadores no processo de acompanhamento e avaliação do plano.

${ }^{16}$ Não foi identificada, nos documentos relativos ao PME de Maricá (2008, 2011), previsão de órgãos/atores sociais a serem envolvidos no processo de acompanhamento e avaliação do plano. 
${ }^{17}$ Não foram identificadas, nos documentos relativos aos PMEs de Niterói (2008; 2010a; 2010b), São Gonçalo (2006a, 2006b, 2006c), Seropédica (2011, 2012) e Tanguá (2009a, 2009b), informações a respeito dos instrumentos a serem utilizados para a consecução do acompanhamento e avaliação dos seus respectivos PMEs. 


\section{Referências}

ARAÚJO, Gilda Cardoso de. Federalismo e políticas educacionais no Brasil: equalização e atuação do empresariado como projetos em disputa para a regulamentação do regime de colaboração. Educação \& Sociedade, Campinas, v. 34, n. 124, p. 787-802, 2013.

ARRETCHE, Marta. Tendências no estudo sobre avaliação. In: RICO, Elizabeth Melo (Org.). Avaliação de políticas sociais: uma questão em debate. São Paulo: Cortez, 1998, p. 29-39.

BARDIN, Laurence. Análise de conteúdo. 3. ed. Lisboa: Edições 70, 2004.

BELLONI, Isaura; MAGALHÃES, Heitor; SOUSA, Luzia Costa de. Metodologia para avaliação de políticas públicas: uma experiência em educação profissional. São Paulo: Cortez, 2001.

BONAMINO, Alicia; FRANCO,Creso; SOUSA, Sandra Zákia; MAIA, Maurício. Avaliação de políticas educacionais. In: BRASIL. Ministério da Educação. Secretaria de Educação Básica. Pradime: Programa de Apoio aos Dirigentes Municipais de Educação. Brasília, DF: MEC/SEB, 2006, p. 133176. (Caderno de Textos 1).

BORDIGNON, Genuíno. Planos de governo e políticas de Estado: muitos planos, pouco planejamento. In: SOUZA, Donaldo Bello de; MARTINS, Ângela Maria (Orgs.). Planos de educação no Brasil: planejamento, políticas, práticas. São Paulo: Loyola, 2014. p. 29-53.

BRASIL. Constituição (1967). Constituição da república Federativa do Brasil. Diário Oficial [da] República Federativa do Brasil, Poder Executivo, Brasília, DF, 24 jan. 1967, p. 1.

. Lei Complementar n ${ }^{\circ} 14$, de 8 de junho de 1973. Estabelece as regiões metropolitanas de São Paulo, Belo Horizonte, Porto Alegre, Recife, Salvador, Curitiba, Belém e Fortaleza. Diário Oficial [da] República Federativa do Brasil, Poder executivo, Brasília, DF, 8 jun. 1973, p. 5585.

Lei Complementar $n^{\circ} 20$, de $1^{\circ}$ de julho de 1974. Dispõe sobre a criação de Estados e Territórios. Diário Oficial [da] República Federativa do Brasil, Poder executivo, Brasília, DF, $1^{\circ}$ jul. de 1974 , p. 7253.

Constituição (1988). Costituição da República Federativa do Brasil. Diário Oficial [da] República Federativa do Brasil, Poder Executivo, Brasília, DF, 5 out. 1988, p. 1.

Constituição (1988). Emenda Constitucional no 1, de 17 de outubro de 1969.Edita o novo texto da Constituição Federal de 24 de janeiro de 1967.Diário Oficial [da] República Federativa do Brasil, Poder executivo, Brasília, DF, 20 out. 1969, p. 8865.

. Lei n 9.394, de 20 de dezembro de 1996. Estabelece as Diretrizes e Bases da Educação Nacional. Diário Oficial [da] República Federativa do Brasil, Poder executivo, Brasília, DF, 23 dez. 1996, p. 27833. 
. Lei $\mathrm{n}^{\circ} 10.172$, de 9 de janeiro de 2001. Aprova o Plano Nacional de Educação (PNE). Diário Oficial [da] República Federativa do Brasil, Poder executivo, Brasília, DF, 10 jan. 2001, p. 1.

- Ministério da Educação. Secretaria de Educação Básica. Documento norteador para elaboração de Plano Municipal de Educação - PME. Brasília, DF: MEC/SEB, 2005.

. Lei n ${ }^{\circ} 13.005$, de 25 de junho de 2014. Aprova o Plano Nacional de Educação - PNE e dá outras providências. Diário Oficial [da] República Federativa do Brasil, Poder executivo, Brasília, DF, 26 jun. 2014, p. 1. Edição extra.

BRITO, Fausto. O deslocamento da população brasileira para as metrópoles. Estudos Avançados, São Paulo, v. 20, n. 57, p. 221-236, 2006.

CARVALHO, Inaiá Maria Moreira de; PASTERNAK, Suzana; BOGUS, Lúcia Machado.Transformações metropolitanas:São Paulo e Salvador.Caderno CRH, Salvador, v. 23, n. 59, p. 301-321, 2010.

COHEN, Ernesto; FRANCO, Rolando. Avaliação de projetos sociais. Petrópolis: Vozes, 1993.

DOURADO, Luiz Fernandes. Avaliação do Plano Nacional de Educação 2001-2009: questões estruturais e conjunturais de uma política. Educação \& Sociedade, Campinas, v. 31, n. 112, p. 677-705, jul./set. 2010.

DRAIBE, Sônia Miriam. Avaliação de implementação: esboço de uma metodologia de trabalho em políticas públicas. In: BARREIRA, Maria Cecília Roxo Nobre; CARVALHO, Maria do Carmo Brant de. (Orgs.). Tendências e perspectivas na avaliação de políticas e programas sociais. São Paulo:PUC, 2001. p. 13-42.

FARIA, Carlos Aurélio Pimenta de. A política da avaliação de políticas públicas. Revista Brasileira de Ciências Sociais, São Paulo, v. 20, n. 59, p. 97-109, out. 2005.

FARIA, Regina. Avaliação de programas sociais: evoluções e tendências. In: RICO, Elizabeth Melo (Org.). Avaliação de políticas sociais: uma questão em debate. São Paulo: Cortez: PUC, 2001.p. 41-49.

GARCIA, Ronaldo Coutinho. Subsídios para organizar avaliações da ação governamental. Planejamento e Políticas Públicas, Brasília, DF, n. 23, p. 7-70, jun. 2001.

HOTZ, Eduardo Fontes.A organização metropolitana pós-constituição de 1988.São Paulo em Perspectiva, São Paulo, v. 14, n. 4, p. 91-98, 2000.

INSTITUTO BRASILEIRO DE GEOGRAFIA E ESTATÍSTICA. Diretoria de Pesquisas. Coordenação de População e Indicadores Sociais. Perfil dos municípios brasileiros 2011. Rio de Janeiro: IBGE, 2012.

ITABORAÍ (Município). Lei no 2.077, de 28 de novembro de 2008. Institui o Plano Municipal de Educação de Itaboraí. Jornal Itaboraí, Itaboraí, n. 138, 29 nov. 2008a. 
. Plano Municipal de Educação de Itaboraí: Anexo da lei nº 2.077, de 28 de novembro de 2008. Itaboraí: Câmara Municipal de Itaboraí, 2008b.

JAPERI (Município). Lei n ${ }^{\circ}$ 1.155, de 10 de abril de 2008. Aprova o Plano Municipal de educação e dá outras providências.Japeri, 10 abr. 2008a. Disponível em: <http://www.japeri.rj.gov.br/PublicFiles/leis/lei2008.pdf>. Acesso em: 19 set. 2017.

- Secretaria Municipal de Educação. Conselho Municipal de Educação. Plano Municipal de Educação: Município de Japeri. Japeri, 2008b. Disponível em: <http://www.japeri.rj.gov.br/PublicFiles/leis/lei2008.pdf>. Acesso em: 19 set. 2017.

KETELE, Jean-Marie de; ROEGIERS; Xavier. Metodologia da recolha de dados: fundamentos dos métodos de observações, de questionários, de entrevistas e de estudo de documentos. Lisboa: Instituto Piaget, 1993. (Coleção Epistemologia e Sociedade).

KIPNIS, Bernardo; ALGARTE, Roberto. Planejamento e avaliação educacionais. In: WITTMANN, Lauro Carlos; GRACINDO, Regina Vinhaes (Coords.). O estado da arte em política e gestão da educação no Brasil 1991-1997. Campinas: Autores Associados; São Paulo: Anpae, 2001. p. 151-171.

LACERDA, Alan Daniel Freire de.Ação coletiva e cooperação intermunicipal em duas metrópoles.Caderno CRH, Salvador. v. 24, n. 61, p. 153-166, 2011.

LAVILLE, Christian; DIONNE, Jean. A construção do saber: manual de metodologia da pesquisa em ciências humanas. Porto Alegre: Artmed; Belo Horizonte: Ed.UFMG, 1999.

LESSARD-HÉBERT, Michelle; GOYETTE, Gabriel; BOUTIN, Gérald. Investigação qualitativa:fundamentos e práticas. 2. ed. Lisboa: Instituto Piaget, 2005.

MARICÁ (Município). Lei no 2.281, de 19 de dezembro de 2008. Aprova o Plano Municipal de Educação. Jornal Oficial de Maricá, Maricá, v. 2, nº 129, 29 dez. 2008.

MARICATO, Erminia. Metrópoles desgovernadas. Estudos Avançados, São Paulo. v. 25, n. 71, p. 7$22,2011$.

- Urbanismo na periferia do mundo globalizado:metrópoles brasileiras.São Paulo em Perspectiva, São Paulo. v. 14, n. 4, p. 21-33, 2000.

MONLEVADE, João Antônio Cabral de. Plano municipal da educação: fazer para acontecer. Brasília, DF: Idéa, 2002.

NILÓPOLIS (Município). Anexo a Lei $n^{o}$ 5.982, de 29 de novembro de 2001: Plano Municipal de Educação. Nilópolis: Secretaria Municipal de Educação, 2001a.

. Lei $\mathrm{n}^{\circ}$ 5.982, de 13 de dezembro de 2001. Aprova o Plano Municipal de Educação com previsão de vigência de 2002 a 2011, e dá outras providências. Jornal A Voz dos Municípios Fluminenses, Nilópolis, 28 dez. 2001 b. 
NITERÓI (Município). Lei n ${ }^{\circ}$ 2.610, de 31 de outubro de 2008. Aprova o Plano Municipal de Educação de Niterói e dá outras providências. A Tribuna, Niterói, $1^{\circ}$ nov. 2008.

. Lei no 2.707, de 25 de março de 2010. Aprova a Complementação do Plano Municipal de Educação de Niterói e dá outras providências. Jornal O Fluminense, Niterói, 25 mar. 2010.

OBSERVATÓRIO DAS METRÓPOLES. Como andam as metrópoles brasileiras: Relatório final Região Metropolitana do Rio de Janeiro. Rio de Janeiro: IPPUR/FASE, dez. 2005. Disponível em: $<$ http://www.observatoriodasmetropoles.ufrj.br/como_anda/como_anda_RM_riodejaneiro.pdf $>$. Acesso em: 16 set. 2011.

. O estado do Rio de Janeiro no Censo 2010: documento preliminar. Rio de Janeiro: IPPUR/ FASE, 2011. Disponível em: <http://www.observatoriodasmetropoles.net/download/documento01_cen so2010RJ.pdf>. Acesso em: 28 dez. 2013.

QUEIMADOS (Município). Lei $n^{o}$ 972, de 24 de dezembro de 2009: Aprova o Plano Municipal de Educação de Queimados e dá outras providências. Queimados, Gabinete do Prefeito, 24 dez. 2009a.

. Secretaria Municipal de educação. Plano Municipal de Educação: Queimados 2009-2019. Queimados, 2009b.

RAMOS, Marília Patta; SCHABBACH, Letícia Maria. O estado da arte da avaliação de políticas públicas: conceituação e exemplos de avaliação no Brasil. Revista de Administração Pública, Rio de Janeiro, v. 46, n. 5, p. 1.271-1.294, set./out. 2012.

RIBEIRO, Luiz Cesar de Queiroz; RODRIGUES, Juciano Martins; CORREA, Filipe Souza. Território e trabalho: segregação e segmentação urbanas e oportunidades ocupacionais na Região Metropolitana do Rio de Janeiro. In: ENCONTRO NACIONAL DE ESTUDOS POPULACIONAIS, 16. Caxambu, 2008. Anais... Campinas: ABEP, 2008. Disponível em: <http://www.abep.nepo.unicamp. br/encontro2008/docsPDF/ABEP2008_1743.pdf>. Acesso em: 16 nov. 2011.

RIBEIRO, Luiz Cesar Queiróz. Desafios daconstrução da cidadania na metrópole brasileira. Sociedade e Estado, Brasília, v. 22, n. 3, p. 525-544. 2007.

RIO DE JANEIRO (Estado). Fundação Centro Estadual de Estatísticas, Pesquisas e Formação de Servidores Públicos do Rio de Janeiro. Anuário estatístico do Estado do Rio de Janeiro 2010. Rio de Janeiro: CEPERJ, 2010 (1 CD-ROM).

. Lei $\mathrm{n}^{\mathrm{o}}$ 5.332, de 24 de novembro de 2008. Dispõe sobre as transferências de receita aos municípios que constituírem o Plano Municipal de Educação. Diário Oficial [do] Estado do Rio de Jnaeiro, Rio de Janeiro, 25 nov. 2008.

. Lei no 5.597, de 18 de dezembro de 2009. Institui o Plano Estadual de Educação - PEE-RJ, e dá outras providências. Diário Oficial [do] Estado do Rio de Janeiro, Rio de Janeiro, 19 dez. 2009a.

- Secretaria Municipal de Educação.Plano Estadual de Educação do Rio de Janeiro. Rio de Janeiro: SME, 2009b. 
RIO DE JANEIRO (Município). Lei no 4.866, de 2 de julho de 2008. Aprova o Plano Municipal de Educação e dá outras providências. Diário Oficial [do] Município do Rio de Janeiro, Rio de Janeiro, 4 jul. 2008a.

. Secretaria Municipal de Educação.Plano Municipal de Educação da cidade do Rio de Janeiro. Rio de Janeiro: SME, 2008b.

ROCHA, Denise Cristina Corrêa da; MONLEVADE, João Antonio Cabral de; AGUIAR Rui Rodrigues. Financiamento e gestão orçamentária da educação. In:BRASIL. Ministério da Educação. Secretaria de Educação Básica. Pradime: Programa de Apoio aos Dirigentes Municipais de Educação. Brasília, DF: MEC/SEB, 2006. p. 73-118. (Caderno de Textos 2).

ROLNIK, Raquel; SOMEKH, Nadia.Governar as metrópoles:dilemas da recentralização.São Paulo em Perspectiva, São Paulo, v. 14, n. 4, p. 83-90, 2000.

SÃO GONÇALO (Município). Lei $\mathrm{n}^{\circ} 56$, de $1^{\mathrm{o}}$ de agosto de 2006. Aprova o Plano Municipal de Educação e dá outras providências. Atos Oficiais - Prefeitura Municipal de São Gonçalo, São Gonçalo, 24 ago. 2006a.

Parecer CME no 005, de 21 de outubro de 2004. Delibera sobre o Plano Municipal de Educação de São Gonçalo. Atos Oficiais - Prefeitura Municipal de São Gonçalo, São Gonçalo, 24 ago. 2006b.

. Plano Municipal de Educação de São Gonçalo - 2004. Atos Oficiais - Prefeitura Municipal de São Gonçalo, São Gonçalo, 24 ago. 2006c.

SARI, Marisa Timm; MARTINS, Ricardo Chaves de Rezende; CASTIGLIONI, Vera Lúcia Baptista. Organização da educação nacional no contexto do fortalecimento da Educação Básica: o papel do município. In: BRASIL. Ministério da Educação. Secretaria de Educação Básica. Pradime: Programa de Apoio aos Dirigentes Municipais de Educação. Brasília: MEC/SEB, 2006. p. 79-130. (Caderno de Textos 1).

SEROPÉDICA (Município). Lei n ${ }^{\circ}$ 426, de 2 de janeiro de 2012. Institui o Plano Municipal de Seropédica. Leis Municipais, [S.1], $1^{\circ}$ jul. 2015. Disponível em:<https://leismunicipais.com.br/a/rj/s/seropedica/lei-ordinaria/2012/43/426/lei-ordinaria-n-4262012-dispoe-sobre-o-plano-municipal-de-educacao-e-da-outras-providencias-2015-07-01-versaocompilada>. Acesso em: 19 set. 2017.

- Prefeitura Municipal. Secretaria Municipal de Educação. PME - Plano Municipal de Seropédica. Seropédica: Prefeitura Municipal de Seropédica, Secretaria Municipal de Educação, 2011.

SOUZA, Celina.Regiões metropolitanas:condicionantes do regime político.Lua Nova: Revista de Cultura e Política, São Paulo, n. 59, p. 137-158. 2003.

SOUZA, Donaldo Bello de; CASTRO, Dora Fonseca. Projeto de investigação "Os Planos Municipais de Educação (Brasil) e as Cartas Educativas Municipais (Portugal)": perspectiva comparada entre as 
Regiões/Áreas Metropolitanas do Rio de Janeiro e do Porto. ver 1.6, Rio de Janeiro: Nephem/FE/Uerj; Porto: InEd/ESE/IPPorto, 2011.

TANGUÁ (Município). Lei no 0717, de 24 de novembro de 2009. Institui o Plano Municipal de Educação. Prefeitura Municipal de Tanguá, Gabinete do Prefeito, Tanguá, 24 nov. 2009a.

. Prefeitura Municipal. Secretaria de Educação, Esporte e Lazer. Plano Municipal de Educação: Tanguá - RJ. Tanguá, 2009b. Mimeo.

URANI, André; AMORIM, Érica; SPERANZA, Juliana; BLANCO, Mauricio. Risco social na Região Metropolitana do Rio de Janeiro: um quadro sobre as condições socioeconômicas das crianças e jovens 1995-2003. Rio de Janeiro: IETS, $2006 . \quad$ Disponível em: <http://www.iets.org.br/biblioteca/Risco_social_na_RM_do_RJ.pdf>. Acesso em: 16 nov. 2011.

VALLE, Bertha de Borja Reis do; MENESES, Janaína Specht da Silva; VASCONCELOS, Maria Celi Chaves. Plano Estadual de Educação do Rio deJaneiro:a trajetória de uma legislação. Rio de Janeiro: Quartet; Outras Letras, 2010.

VASCONCELOS, Maria Celi Chaves; PEIXOTO, Leonardo Ferreira; VIDAL, Patrícia Evaristo. Conselhos Municipais de Educação no estado do Rio de Janeiro: uma análise comparativa a partir do Sicme. In: VALLE, Bertha de Borja Reis do; VASCONCELOS, Maria Celi Chaves (Orgs.). Conselhos Municipais de Educação: organização e atribuições nos sistemas de ensino do Estado do Rio de Janeiro. Rio de Janeiro: Quartet/Faperj, 2012. p. 305-339.

VIANA, Ana Luiza. Abordagens metodológicas em políticas públicas. Revista de Administração Pública, Rio de Janeiro, v. 30, n. 2, p. 5-43, mar./abr. 1996.

YANG,Rui.Comparaçõesentrepolíticas.In: BRAY, Mark; ADAMSON, Bob; MASON, Mark (Orgs.). Pesquisaemeducaçãocomparada:abordagensemétodos.Brasília,DF:LiberLivro,2015.p.319-343. 
Metropolitan Municipal Plans of Education: challenges to the follow-up and local evaluation

\begin{abstract}
This article aims the analysis of the future prospect and the challenges related to the follow-up and local evaluation of PMEs, taking as a basis the belonging plans of ten municipalities of the Metropolitan Area of Rio de Janeiro approved in the period of 2001-2012. Based on the analysis of these documents, notes a concern on these plans to display the participation of various social agents in their elaboration, as well as in the framework of their systematic monitoring and evaluation, in spite of the fact that they do not attribute centrality to CMEs as a privileged locus to achieve these actions.
\end{abstract}

Keywords: Municipal Plans of Education (PME). National Plan of Education (PNE). follow-up and evaluation.

\section{Donaldo Bello de Souza}

E-mail: donaldobello@gmail.com

Alzira Batalha Alcântara

E-mail: alzirabatalha@hotmail.com
Planes Municipales de Educación metropolitanos: desafíos al acompañamiento y evaluación local

\section{Resumen}

Este artículo tiene el objetivo de analizar la previsión y los desafíos relativos al acompañamiento y evaluación local de PMEs, sobre la base de los planes pertenecientes a diez municipios de la Región Metropolitana del Rio de Janeiro, aprobados en el periodo 2001-2012. Pautado en el análisis del contenido de eses documentos, destaca la preocupación de estos planes en resaltar la participación de diversos actores socialesen su preparación, como también en el pronóstico de su seguimiento y evaluación sistemática, aunque no hay la atribución de centralidad a las CMEs como un locus privilegiado para la consecución de estas acciones.

Palabras-clave: Plan Municipal de Educación (PME). Plan Nacional de Educación (PNE). Acompañamiento y evaluación.

Enviado em: 26/11/2015

Versão final recebida em: 10/04/2017

Aprovado em: 11/04/2017 